\title{
Clinical factors associated with dementia in ischaemic stroke
}

\author{
G LADURNER, LD ILIFF, H LECHNER \\ From the Department of Psychiatry and Neurology, Graz University, Graz, Austria
}

SUMMARY 71 patients with an ischaemic stroke were studied. The patients were separated into two groups on the basis of the results of clinical investigation, computed tomography and psychological testing (WAIS). 40 patients showed an early dementia and 31 were without mental impairment. The mean age was 57 years in the demented group and 54 years in the non-demented group. The mean duration of the history of cerebrovascular disease was also not statistically different in both groups. The frequency of strokes was identical since $50 \%$ of the patients in both groups had more than one stroke. The history of neurological symptoms together with the neurological deficits seen on admission were distributed evenly. The dominant hemisphere was more often diseased in the demented group. Bilateral symptoms were also more common in the demented stroke patients. The WAIS showed a similar IQ in both groups but the deterioration index was significantly altered in the demented group. Hypertension was the only risk factor which differed between both groups. Cardiac disease, diabetes, viscosity and fibrinogen did not differ in both groups. The CT showed more normal scans in the non-demented group, the distribution of atrophy on its own and infarction in the left or right hemisphere were both inconclusive, whilst patients with bilateral infarcts were more common in the dementia group. Also, generalised atrophy in combination with an infarct was found more often in the demented patients.

Epidemiological studies have shown that dementia is present in between $4.4-8 \%$ of the population over the age of 65 years. ${ }^{1-3}$ The occurrence of dementia increases with age, from $2.3 \%$ in people of $65-69$ years to $22 \%$ in those aged 80 years or older. ${ }^{1}$

Pathological studies have shown that dementia is caused by primary degenerative disease in $50 \%$ of the cases in contrast to $20-22 \%$ being caused by cerebrovascular disease. ${ }^{5}$ Clinical investigations, however, have shown cerebrovascular disease to be the cause of dementia more often than primary degenerative disease. ${ }^{2} 6$

Because only some patients with cerebrovascular disease eventually develop dementia, it would seem important to study the processes leading to, or associated with, dementia. This type of dementia was called "multi-infarct" dementia because it is

Address for reprint requests: G Ladurner, Department of Psychiatry and Neurology, Graz University, A-8036 Graz, Auenbruggerplatz 22, Austria.

Received 15 February 1981 and in revised form 31 August 1981

Accepted 1 November 1981 considered to be the result of multiple infarcts ${ }^{7}$ with perhaps a particular distribution. ${ }^{8}$ Another factor associated with dementia was a reduced mean cerebral blood flow with changes in the focal pattern. ${ }^{9-11}$ These findings, however, also can be seen in patients with a stroke but in the absence of dementia, so it is logical to compare groups of stroke patients with and without dementia to try to clarify the clinical and morphological factors leading to dementia.

\section{Material and methods}

Seventy-one patients with an ischaemic stroke were studied. In all patients neurological, psychological (WAIS), psychiatric and computed tomographical (EMI Scanner CT 1010) investigations were performed. In four patients (table 1) no history of focal neurological symptoms was evident so that the diagnosis of ischaemic stroke was based only on the CT which showed an infarct. In 67 patients there was a history of at least one ischaemic episode with focal neurological symptoms in 66 cases.

The patients were separated into two groups on the basis of the results of clinical investigation, the CT study and CBF and angiography when available. Only patients 
Table 1 Neurological history

\begin{tabular}{lccc}
\hline $\begin{array}{l}\text { Neurological } \\
\text { symptoms }\end{array}$ & Number & \multicolumn{2}{l}{ Ischaemic stroke } \\
\cline { 3 - 4 } & & With dementia & Without \\
\hline None & 4 & 2 & 2 \\
Non-focal & 1 & 1 & - \\
Focal & 66 & 37 & 29 \\
Total & 71 & 40 & 31 \\
\hline
\end{tabular}

who were capable of performing the psychological test (WAIS) were included and 31 of the total of 71 had normal results. The remaining 40 showed mild (early) dementia. The mean age of the demented patients was 57 years (SD \pm 11.4$) ; 27$ were females and 13 males. The mean age of the non-demented patients was 54 years $(\mathrm{SD} \pm 11 \cdot 8)$, with 17 females and 14 males.

In the majority of patients a recent stroke was the reason for admission to hospital. However, the mean time interval between the first stroke with the start of psychiatric symptoms (duration of disease) and investigation of the patients was 1.9 years $(S D \pm 3.8)$ in the nondemented and $2 \cdot 3(\mathrm{SD} \pm 3 \cdot 1)$ years in the demented patients. The relevant clinical data such as the history, neurological findings and localisation of the infarct (dominant or non-dominant hemipshere) were investigated. Vascular "risk factors" were investigated including hypertension (BP values of $165 / 95 \mathrm{~mm} \mathrm{Hg}$ or above), cardiac disease, diabetes, viscosity (cone plate viscometer, shear rate $11.5 \mathrm{~s}^{-1}$ ) and fibrinogen (Behring). A psychological test (WAIS) was also performed. Loss of mental capabilities was defined by the division of the "stable" part of the test by the "unstable" part. This index is called the "deterioration index" and is considerably altered by the presence of organic brain disease. ${ }^{12}$ The CT findings were divided into normal scans, atrophy alone, unilateral infarction (with or without atrophy), and bilateral infarction without any consideration of atrophy. Statistical evaluation was by the $\chi^{2}$ and Student $t$ test.

\section{Results}

\section{CLINICAL FINDINGS}

The frequency of strokes (table 2) was identical in both groups since $50 \%$ of the patients both in the demented and non demented group had more than one stroke. Of interest was the fact that in four patients from both groups (two with, two without dementia) no history of focal neurological symptoms could be found. They only had symptoms such as vertigo, dizziness, drop attacks or headache in their history but a definite infarct was evident in the CT. Neurological deficits were described in the history (table 1) in all but four patients. One patient had a history of a non-focal neurological deficit. The distribution of the focal and non-focal symptoms in the histories were similar both in the demented and non-demented groups.
Table 2 Frequency of strokes

\begin{tabular}{lrrr}
\hline $\begin{array}{l}\text { Frequency of } \\
\text { strokes/TIA }\end{array}$ & Number & \multicolumn{2}{l}{ Ischaemic stroke } \\
\cline { 2 - 4 } & & With dementia & Without \\
\hline 1 & 36 & 21 & 15 \\
2 & 24 & 12 & 12 \\
3 & 7 & 5 & 2 \\
4 (or more) & 4 & 2 & 2 \\
Total & 71 & 40 & 31 \\
\hline
\end{tabular}

Neurological symptoms on admission (table 3) were shown in 49 patients whilst 22 had none. Focal neurological signs in the patients were evenly distributed; there being 25 in the demented group and 21 in the non-demented group.

Table 3 Neurological symptoms on admissionfocal/non-focal

\begin{tabular}{lccl}
\hline $\begin{array}{l}\text { Neurological } \\
\text { symptoms }\end{array}$ & Number & \multicolumn{2}{l}{ Ischaemic stroke } \\
\cline { 3 - 4 } & & With dementia & Without \\
\hline None & 22 & 12 & 10 \\
Non-focal & 3 & 3 & -1 \\
Focal & 46 & 25 & 21 \\
Total & 71 & 40 & 31 \\
\hline
\end{tabular}

Dominant versus non-dominant hemispheric symptoms (table 4) There were more dominant hemisphere lesions and bilateral lesions in the demented patients. Epileptic seizures were present in nine patients, five with and four without dementia. Both groups had three cases with generalised seizures whereas there were three patients with partial seizures in the demented group, and only one patient with partial seizures in the non-demented group.

Table 4 Neurological symptoms dominant versus non-dominant hemisphere involvement

\begin{tabular}{|c|c|c|c|}
\hline \multirow[t]{2}{*}{ Neurological symptoms } & \multirow[t]{2}{*}{ Number } & \multicolumn{2}{|c|}{ Ischaemic stroke } \\
\hline & & $\begin{array}{l}\text { With } \\
\text { dementia }\end{array}$ & Without \\
\hline Without aphasia & 12 & 6 & 6 \\
\hline Dominant hemisph & & & \\
\hline With aphasia & 27 & $18^{\prime}$ & 9 \\
\hline Non-dominant hemisph & 17 & 4 & 13 \\
\hline Bilateral & 10 & $9 *$ & 1 \\
\hline Total & 66 & 37 & 29 \\
\hline
\end{tabular}

*p $<0.05$.

tp $<0.01$.

\section{THE WAIS TEST}

The psychological test (table 5) when averaged for all the patients in each group showed no difference with regard to the mean $I Q$. The deterioration index ${ }^{12}$ showed a difference in both groups emphasising the decline of unstable subtests in the WAIS as opposed to the stable subtests. 
Table 5 Psychological test (WAIS)

\begin{tabular}{lll}
\hline Test $($ WAIS $)$ & \multicolumn{2}{l}{ Ischaemic stroke } \\
\cline { 2 - 3 } & With (40) & Dementia without (3I) \\
\hline IQ & 90 (SD 14) & 94 (SD 10) \\
Deterioration index & $74^{*}$ (SD 20) & 92 (SD 10) \\
\hline
\end{tabular}

${ }^{*} \mathrm{p}<0.001$.

\section{RISK FACTORS}

Hypertension was the only risk factor which showed a highly significant difference between demented and non-demented stroke patients (table 6). Cardiac disease, diabetes, the viscosity and fibrinogen were no different in the two groups.

Table 6 Cerebrovascular risk factors

\begin{tabular}{lll}
\hline Risk factors & \multicolumn{2}{l}{ Ischaemic stroke } \\
\cline { 2 - 3 } & W'ith $(40)$ dementia & Without $(31)$ \\
\hline Hypertension & & \\
$\quad(165 / 95$ mm Hg) & $27^{*}$ & 7 \\
Cardiac disease & 14 & 8 \\
Diabetes & 8 & 3 \\
Viscosity (mNsm-2) & $8 \cdot 7$ & $8 \cdot 5$ \\
Fibrinogen $(\mathrm{mg} / 100 \mathrm{ml})$ & 338 & 337 \\
\hline
\end{tabular}

$* \mathrm{p}<0.001$.

\section{COMPUTED TOMOGRAPHY}

CT showed more normal scans in the non-demented group (table 7). The distribution of atrophy alone and infarction in the left or right hemisphere were both inconclusive, whilst patients with bilateral lesions were more common in the dementia group. The infarcts in both groups were mainly small in size and located in the basal ganglia, including sometimes the internal capsule or in watershed areas. In addition to the higher number of infarcts present in the demented patients, this group also showed a higher proportion of infarcts in the thalamus as compared with the non-demented patients. In five patients with dementia CT showed a combination of hypodense areas in the white matter with small infarcts, a picture which is considered to be typical of Binswangers subcortical encephalopathy. Atrophy without infarction (table 8) was distributed similarly in both groups. Generalised atrophy, that is to say cortical atrophy as well as ventricular enlargement, was predominant. Generalised atrophy was also the main type of atrophy combined with an infarct and also was more often present in the demented patients.
Table 7 Computed tomographic findings: infarct ischaemic stroke

\begin{tabular}{lclc}
\hline Computed tomography & Number & \multicolumn{2}{l}{ Ischaemic stroke } \\
\cline { 3 - 4 } & & $\begin{array}{l}\text { With } \\
\text { dementia }\end{array}$ & Without \\
\hline Normal & 9 & 2 & $7 *$ \\
Atrophy only & 13 & 9 & 4 \\
$\quad$ Right & 19 & 8 & 11 \\
Infarct left & 14 & 8 & 6 \\
$\quad$ Bilateral & 16 & $14 \dagger$ & 2 \\
Total & 71 & 40 & 31 \\
\hline p $<0.05$. & & & \\
tp $<0.01$. & &
\end{tabular}

Table 8 Computed tomographic findings: atrophy

\begin{tabular}{|c|c|c|c|}
\hline \multirow[t]{2}{*}{ Computed tomography } & \multirow[t]{2}{*}{ Number } & \multicolumn{2}{|c|}{ Ischaemic stroke } \\
\hline & & $\begin{array}{l}\text { With } \\
\text { dementia }\end{array}$ & Without \\
\hline Normal & 9 & 2 & $7 *$ \\
\hline Infarct only & 11 & 5 & 6 \\
\hline \multicolumn{4}{|l|}{ Atrophy only } \\
\hline Ventricle & 1 & 一 & 1 \\
\hline Cortical & 1 & 1 & - \\
\hline General & 11 & 7 & 4 \\
\hline \multicolumn{4}{|l|}{ Atrophy with infarct } \\
\hline Ventricle & 14 & 8 & 6 \\
\hline Cortical & 1 & - & 1 \\
\hline General & 23 & $17^{*}$ & 6 \\
\hline Total & 71 & 40 & 31 \\
\hline
\end{tabular}

$* \mathrm{p}<0.05$.

\section{Discussion}

The term "multi-infarct dementia" seems to be appropriate for our patients with dementia since $50 \%$ of them had more than one stroke. This finding is supported by other investigations in which the CT showed $60 \%$ of the patients with vascular dementia had multiple infarcts. 81314 There remains, however, the problem that CT showed that the frequency of strokes and the occurrence of multiple infarcts in one hemisphere only is the same in patients with ischaemic stroke but no intellectual impairment as in the demented patients. ${ }^{8}$ Atrophy only in the CT scans, without any sign of an infarct, was similarly distributed in the demented and non-demented patients. Atrophy with an infarct, especially generalised atrophy, was more common in the demented patients. This indicates the importance of general loss of tissue. Apart from the quantitative factor of the loss of substance there is also a qualitative factor in the distribution of infarcts. The occurrence of bilateral infarcts (shown both clinically and by CT) demonstrated a difference between the two groups in that bilateral infarction was more common in the dementia patients. The importance of bilateral 
lesions was also supported by cerebral blood flow studies showing a bilateral reduction of cerebral blood flow in dementia.11 1516 The distribution of the mainly small infarcts in both groups was predominant in the basal ganglia and the watershed areas. In addition to the higher number of infarcts in the demented patients, they also showed a higher proportion of infarcts in the thalamus as compared with the non-demented patients. This may explain the fact that only $50 \%$ of the patients with dementia had multiple infarcts. Some of the infarcts might have happened without clinical sign of a focal neurological deficit. In this respect the CT findings of four patients without focal neurological symptoms seem to be relevant, showing that loss of tissue through cerebrovascular disease can be insignificant neurologically, but important for the psychiatric picture. The bilateral pattern of the distribution of the lesions is not always represented by a bilateral infarction, but by the combination of generalised atrophy and a single infarct. ${ }^{8}$ The latter situation might also include patients with infarcts on the normal side in CT which were too small to be detected or not visualised for other reasons. ${ }^{17-19}$ Another possibility could be focal neurological deficits combined with hypertension, constituting the clinical and CT picture of Binswangers subcortical encephalopathy. ${ }^{20}$ The corresponding CT picture ${ }^{20}$ was seen in five of our patients which were all in the demented group. Finally, a combination of primary degenerative dementia and cerebrovascular disease is possible in about $10 \%$ of the patients with dementia. 4521

Another difficult area is the differential diagnosis of an old infarction and intracerebral haemorrhage which is clinically diagnosed incorrectly in $30 \%$ of patients at the acute stage investigated by CT. ${ }^{22}$ The patient with multi-infarct dementia is often seen when several additional strokes have taken place, by which time the differential diagnosis of the old lesion, be it an infarct or a haemorrhage, is impossible even using CT. Additionally, the CT diagnosis of haemorrhagic infarcts in $7 \%$ of the 631 patients with infarcts ${ }^{23}$ might, together with a previously undiagnosed intracerebral haematoma, lead to secondary phenomena like the development of normal pressure hydrocephalus. This possible source of secondary neuronal damage and the question of intracerebral haemorrhage resulting in multi-infarct dementia need further investigation.

We conclude that in using the clinical term multiinfarct dementia, emphasis should not only be laid on the loss of substance, either through infarction or by generalised atrophy, but also on qualitative facts such as the bilateral distribution of infarcts, involvement of the thalamus, and the possibility of secondary phenomena adding to the neuronal loss.

\section{References}

${ }^{1}$ Kay DWK, Foster EM, Mc Kennie AA, Roth M. Mental illness and hospital usage in the elderly. Compr Psychiatry 1970;11:26-35.

2 Broe GA, Akhtar GR. Neurologic disorders in the elderly at home. $J$ Neurol 1976;39:362-6.

${ }^{3}$ Tower DB. Alzheimer disease-senile dementia and related disorders. In: Katzman R, Terry RD, Bick KL, eds. Alzheimer's disease. New York: Raven 1978.

4 Tomlinson BE, Blessed G, Roth M. Observations on the brain of demented old people. $J$ Neurol Sci 1970; $11: 205-42$.

5 Jellinger K. Neuropathological aspects of dementia resulting from abnormal blood and cerebrospinal fluid dynamics. Acta Neurol Belg 1976;76:83-102.

${ }^{6}$ Ladurner G, Lechner H, Iliff LD, Pieringer W. Computertomography in Psychiatry. Neurol Psychiat 1980;3:23-7.

${ }^{7}$ Hachinski VC, Iliff LD, Zilkha E, McAllister VL, Du Boulay GH, Marshall J, Ross Russel RW, Symon L. Cerebral blood flow in dementia. Arch Neurol 1975; 32:632-7.

${ }^{8}$ Ladurner G, Sager WD. Morphologische Bedingungskonstellation der vaskulären (Multiinfarkt) Demenz. Fortschr Neurol Psychiatr 1981 ;49:53-5.

- Ingvar DH, Gustafson L. Regional cerebral blood flow in organic dementia with early onset. Arch Neurol Scand 1970; (Suppl. 43)46:42-73.

${ }^{10}$ Lechner H, Ladurner G, Ott E, et al. Regional cerebral blood flow in dementia. In: Cerebral Vascular Disease. Meyer JS, Lechner H, Reivich M, eds. Stuttgart: Thieme 1976.

11 Ladurner G, Ott E, Perry PJ, et al. Bilateral measurement of rCBF in dementia. In: Cerebral Vascular Disease. Meyer JS, Lechner H, Reivich M, eds. Amsterdam: Excerpta Medica 1977.

12 Baxa W, Pakesch E. Mitteilung über die Verwendung eines Index am HAWIE zur Bestimmung einer sekundären Intelligenzreduzierung. $\mathrm{Wr} Z$ Nervenheilk 1972;30:119-30.

${ }^{13}$ Ladurner G, Sager WD, Iliff LD, Lechner H. A correlation of clinical findings and CT in ischaemic cerebrovascular disease. Europ Neurol 1979;18:2818.

14 Ladurner G, Bertha G, Pieringer W, Lytwin H, Lechner H. Klinische Unterscheidungskriterien bei vaskulärer (Multiinfarkt) und primär degenerativer Demenz (Alzheimer). Nervenarzt 1981;52:401-4.

15 Munck O, Lassen NA. Bilateral cerebral blood flow and oxygen consumption in Man by use of Krypton. Circ Res 1957;5:163-8.

${ }^{16}$ Lassen NA, Feinberg I, Lane MH. Bilateral studies of cerebral oxygen uptake in young and aged normal subjects and in patients with organic dementia. J Clin Invest $1960 ; 39: 491-500$.

17 Alcala H, Gado M, Torack RM. The effect of size, histologic elements and water content on the visualisation of cerebral infarcts. Arch Neurol 1978; 35:1-8.

18 Ladurner G, Sager WD, Höfler H, et al. CT correlation with anatomic pathology in stroke and cerebro- 
vascular disease. In: Cerebral Vascular Disease 2nd ed. Meyer JS, Lechner H, Reivich M, eds. Amsterdam: Excerpta Medica 1979.

${ }^{19}$ Höfler H, Walter G, Ladurner G, Sager WD. Korrelation von Obduktions- und CT Befunden bei zerebrovaskulären Erkrankungen. In: Computertomographie. Sager WD, Ladurner, G eds. Stuttgart : Thieme 1979.

${ }^{20}$ Zeumer H, Schonsky B, Sturm KW. Predominant white matter involvement in subcortical arteriosclerotic encephalopathy (Binswanger disease).
J Comput Assist Tomogr 1980;4:14-9.

${ }^{21}$ Butler R. Alzheimer disease-senile dementia and related disorders. In: Alzheimer's disease. Katzman R, Terry RD, Bick KL, eds. New York: Raven 1978.

${ }^{22}$ Kinkel WR, Jacobs L. Computerized axial transverse tomography in cerebrovascular disease. Neurology (Minneap) 1976;26:924-30.

${ }^{23}$ Sager WD, Ladurner G. Klassifikation und Verlauf des Hirninfarktes im Computertomogramm. Fortschritte Röntgenstrahlen Nuklearmedizin 1979;131:470-5. 